\title{
Consequence of land use changes into energy crops in Campania region
}

\author{
Stefania Pindozzi, Salvatore Faugno, Elena Cervelli, Alessandra Capolupo, Maura Sannino, \\ Lorenzo Boccia
}

Dipartimento di Agraria, Università di Napoli Federico II, Italy.

\begin{abstract}
Campania region is undergoing a new and important land use change (LUC). Large areas under tobacco are experiencing a severe economic crisis and cereal areas, especially in the hill, are cultivated with increasing difficulty, with poor economic results (yield value of $2.5 \mathrm{t} / \mathrm{h}$ /year) and under the risk of erosion. No-food crops suitable in these contexts are the perennial and in this case, the land use change would certainly lead to a positive impact on reducing erosion, but also on the reduction of nutrient requirement, on fuel consumption and perhaps it would also lead to an increase in profitability. The aim of this work is to identify the areas in which the land use change could be realistic and ecologically compatible and to evaluate the main consequence of the LUC. The study area includes the entire Campania region. It has been assumed that the areas that will undergo the LUC will be the hilly, not-irrigated cereal crop, with altitudes between 400 and $750 \mathrm{~m}$ a.s.l., not included in natural parks, in the Site of Community Importance and in the Special Protection Areas. Through the climate model, inferred from the Ground Water Protection Plan, the area to be examined was classified as 'cold Lauretum', which is a good area for the Arundo donax crops up to $750 \mathrm{~m}$ a.l.s., with recoverable biomass yield of about 12.6 t/year. The erosion has been estimated
\end{abstract}

Correspondence: Lorenzo Boccia, DIA, Università degli Studi di Napoli Federico II, via Università 100,80055 Portici (NA), Italy.

Tel. +39.081.2539151.

E-mail: lorenzo.boccia@unina.it

Key words: land use change, energy crops, Arundo donax.

Contributions: the authors contributed equally.

Conflict of interests: the authors declare no potential conflict of interests.

Funding: the work was supported by Italian Ministry of Education, University and Research. with the PON Project.

Acknowledgments: this research was realized under PON Project 01_01966 "Integrated agro-industrial chains with high energy efficiency for the development of eco-compatible processes of energy and bio-chemicals production from renewable sources and for the land valorization (ENERBIOCHEM)" funded by Italian Ministry of Education, University and Research.

CC Copyright S. Pindozzi et al., 2013

Licensee PAGEPress, Italy

Journal of Agricultural Engineering 2013; XLIV(s2):e93

doi:10.4081/jae.2013.s2.e93

This article is distributed under the terms of the Creative Commons Attribution Noncommercial License (by-nc 3.0) which permits any noncommercial use, distribution, and reproduction in any medium, provided the original author(s) and source are credited. with RUSLE applied to the whole region. Using the ESRI ArcGis 10.0 software, seven large areas, partially convertible, were identified. The area that is realistic to convert amounted to approximately $500 \mathrm{~km} 2$. The value of the biomass production has been evaluated in the order of 25 million euro a year; actual wheat production would be 33 million euro a year but the production costs are far greater.

With LUC there is a reduction in soil erosion in the order of 300000 tyear. This would lead a saving, on global scale, in the order of 10 million tonnes of $\mathrm{CO}_{2}$ per year.

\section{Introduction}

We are certain that Campania region, one of the most important agricultural territory in Italy, is undergoing a new and major Land Use Change (LUC). The analyses of LUC are crucial to understanding several environmental phenomena (Lambin et al. 2001; Pelorosso et al. 2009) but also to develop the prediction of the new change. The driving forces of the change that we expect, are fundamentally related to economic and social change. Large areas under tobacco and cereals are experiencing a severe economic crisis, especially in the hilly places, which are cultivated with increasing difficulty, with poor economic results and under the risk of erosion (Diodato et al.. 2009).

The new LUC will be the consequence of a complex and impetuous LUC that was well studied and analyzed in the past (Di Gennaro and Innamorato, 2005). The further changes that we expect, will take place in an area that has experienced a period of deep transformation in the last forty years, under the pressure of opposite forces, such as the unregulated urban expansion, the intensification and the specialization of agricultural production activities (Fabiani and Favia, 1990; I sistemi di terre della Campania, 2002; Di Gennaro and Innamorato, 2005). The areas that will undergo the land use change, are those that are no longer cost effective for food crops, such as the erosion prone areas under cereal production, in which the no-food crops would also have an environmental value (Fagnano et al.,2012 a).

The main driving forces of this process are related to economic factor and to the reduction in the number of farmers in some context, especially in the interior part of the region, far from the main cities. But in some context, there are other driving forces of the LUC. The first is that some areas are polluted due to illegal contamination or fallout of particulates and pollutants as a consequence of illegal burning of waste. The second is that some irrigated areas have problems of salinity, as a result of excessive withdrawal of groundwater. Considering the incentives for no-food energy crops, it is most likely that in short time some of these areas will be subjected to LUC.

No-food crops suitable in these contexts are the perennials, and the land use change would certainly lead to a positive impact of reducing erosion, but also on the reduction of nutrient requirement, fuel consumption and perhaps it would also lead to increased profitability.

Several studies have demonstrated that in the interior areas of Campania region, the rain erosivity is higher during the months of 
September-October (Diodato et al.., 2009), which correspond to the period of maximum erodibility of soils also due to the traditional wheat cultivation technique, which provides for the absence of vegetation during these months. As a matter of fact, $80 \%$ of the annual erosion occurs during this period. In addition, the wheat yield in these areas is very low (yield value of about $2.5 \mathrm{t} / \mathrm{h}$ /year). Consequently these crops do not seem to be sustainable, in the long term, from an economical and environmental point of view (Fagnano et al., 2012b). No-food crops suitable in these contexts are the perennials and then the land use change would certainly lead to a positive impact of reducing erosion, but also on the reduction of nutrient requirement, on fuel consumption and perhaps an increase in profitability, if under a proper incentive mechanism.

With this background, the aim of this work is to identify the areas in which the land use change could be realistic and ecologically compatible and to evaluate the main consequences of the new land cover mainly in terms of erosion risk reduction.

\section{Materials and methods}

\section{Area of study}

The study area included the whole Campania region, because the Common Agricultural Policy boundary is the same as the administrative boundary and also because the habitat and topography, change largely due to changes in the surrounding regions. The total area of the territory is about $13,600 \mathrm{~km}^{2}$, and is made up of mountains, $34.6 \%$, hills, $51 \%$, and plains, $15 \%$. It was assumed that the areas that will undergo the land use change are the hilly cereal growing areas with altitudes between 400 and 750 meters above sea level.

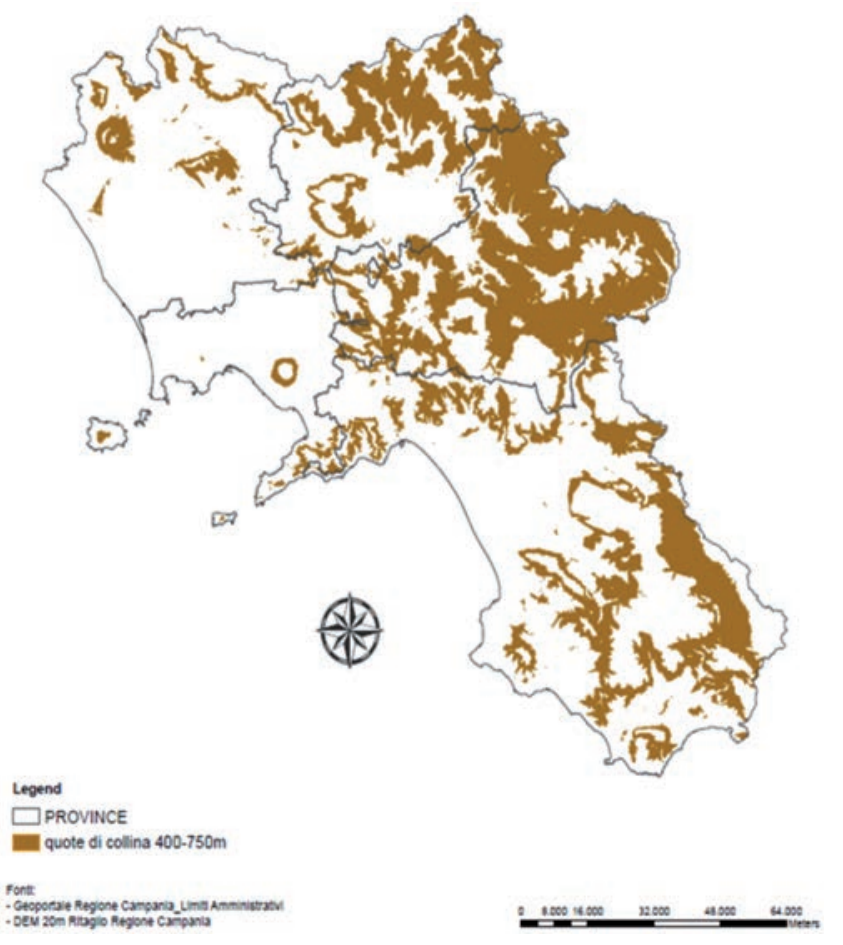

Figure 1. Hill areas, with altitudes between 400 and 750 meters above sea level (DEM of Campania).
One of the GIS layers used for the land use change study, was derived from the CORINE Land Cover (CLC). The land use map was filtered in ArcGis in order to select the non-irrigated cereal land (Figure 1). Moreover the hilly areas, from the height of 400 to 750 meters above sea level, were obtained by filtering the Digital Elevation Model (DEM) of the Campania region at $20 \mathrm{~m}$ resolution (Figure 2).

The eligible areas for land use change was identified by filtering the non-irrigated crop, with altitudes between 400 and $750 \mathrm{~m}$ a.s.l., excluding the National Parks, Site of Community Importance (SCI) and Special Protection Areas (SPA).

\section{Climate conditions and suitable crops}

The climate model was inferred from the Ground Water Protection Plan (PTA) of the Campania region. The climate in the study areas, can be approximated by the following linear functions:

Mean Annual Temperature $=16.5-0.006$ height (m.a.s.l.)

Mean Annual Rainfall $=750 \mathrm{~mm}+$ height $\mathrm{K}_{2}$

with $\mathrm{K}_{2}=$ Coefficient that ranges from 0.40 to 0.70 .

Therefore, according to the De Philippis's classification (1937), this area can be classified as 'cold Lauretum', which is a good for the Arundo donax crops up to $750 \mathrm{~m}$ a.l.s., with recoverable biomass yield in the order of 12.6 t/year after the third year. For hilly wheat areas, a yield value of $2.5 \mathrm{t} / \mathrm{ha} / \mathrm{year}$ was considered.

\section{Restrictions}

The following shapefiles of Campania region were used for the selection of the areas to be converted: natural parks, protected areas (Figure 3), Site of Community Importance (SCI) (Figure 4) and Special Protection Area (SPA) (Figure 4). These layers were imported into ArcGIS in order to exclude them, since they are assumed non-con-

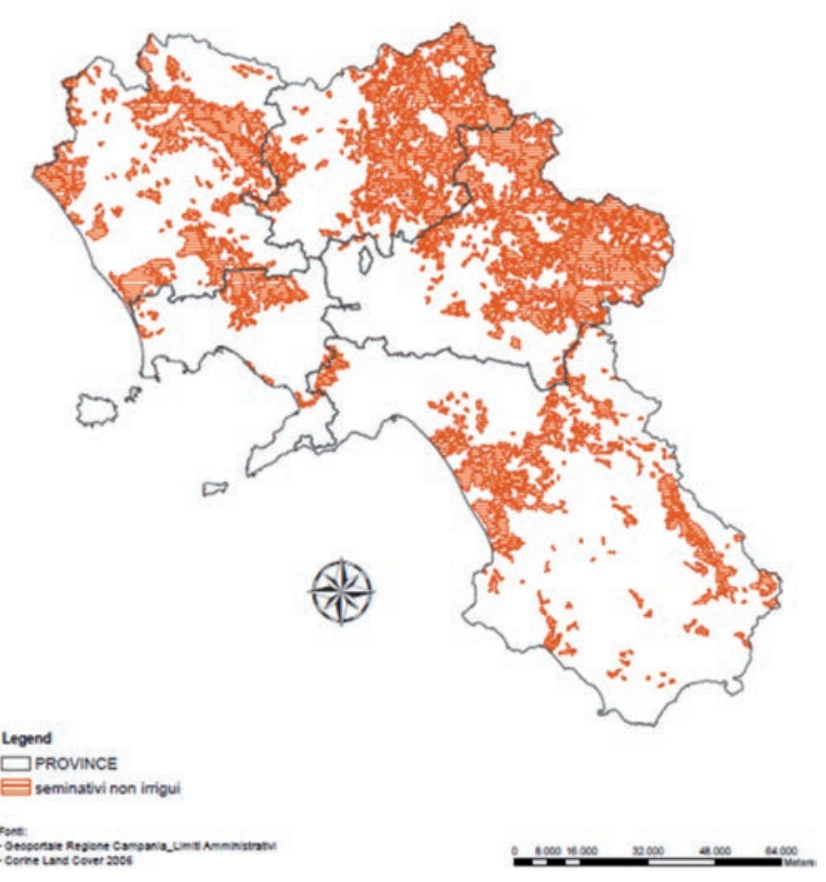

Figure 2. Areas cropped with cereals (CORINE Land Cover). 
vertible to energy crops. It's important to note that future management of SCI and SPA could allow the land use change into biomass, but it is not certain, and at date it is correct to exclude these areas.

\section{Soil erosion risk prediction}

The soil erosion prediction map was evaluated using RUSLE equation, (Wischmeier, 1959; Wischmeier et al., 1969,1971,1978; Summer et al., 1998) which is not a physically based model, is:

$$
\mathrm{A}=2.24 \mathrm{R} \mathrm{K} \mathrm{L} \mathrm{S} \mathrm{C} \mathrm{P,}
$$

where, $A$ is the average annual soil loss (t/ha/year), $R$ estimates the rainfall erosivity, $K$ estimates the soil erodibility, $L$ is the hill slope, $S$ estimates the hill slope gradient, $C$ is the ground cover factor and estimates the soil susceptibility to the erosive agents and $P$ represents the effect given by any conservative practices of canalization or cultivation. For each parameter, an algorithm was suggested for application to the whole region.

In these areas, erosion has been estimated with the current land use (cereals) compared to the erosion that would occur if the land use were converted to permanent crop.

\section{Methods for estimating the energy potential}

The energy potential was predicted for both energy crop and straw, assuming that is possible to collect the straw for energy use

The energy potential of Arundo donax, is about 185,000 toe/year (toe is ton of oil equivalent), that was calculated assuming collection $42 \%$ of production with moisture content of $30 \%$, with a lower heat value (LHV) for dry biomass of $17.6 \mathrm{MJ} / \mathrm{kg}$. In the case of straw, the value is 70,000 toe/year assuming $90 \%$ of the production can be collected and moisture content of $15 \%$.

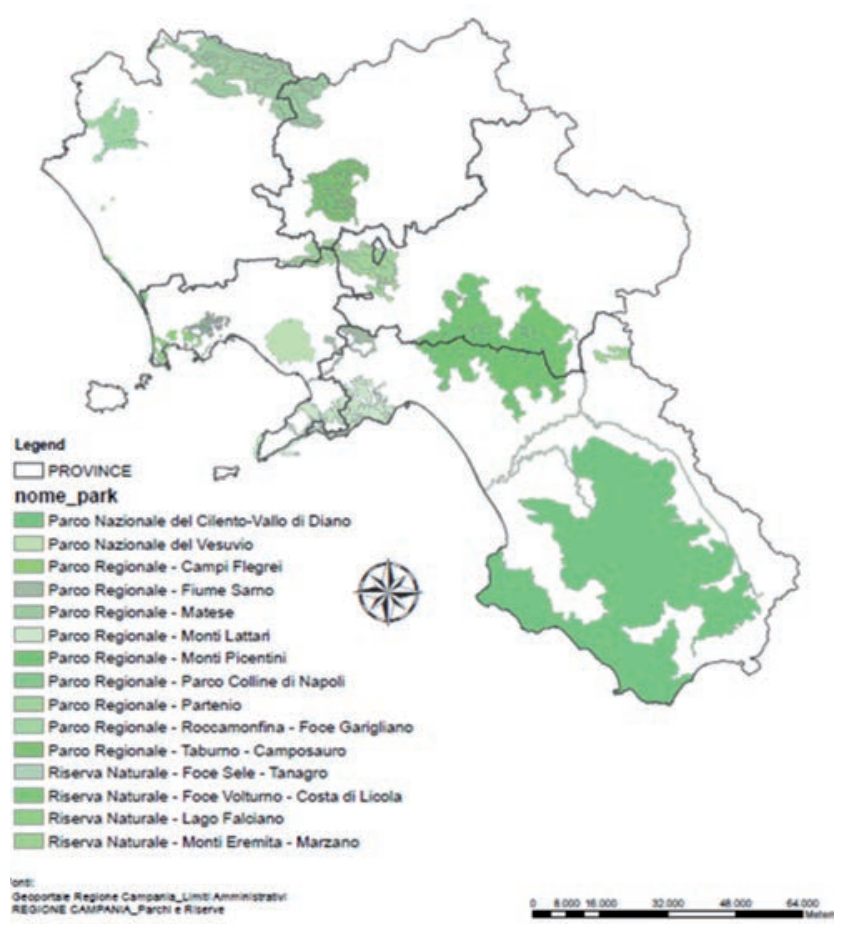

Figure 3. Natural parks and reserves.

\section{Results and discussion}

Filtering the maps of the studied territory, some areas were identified. For industrial use, only the areas in which it is possible to organize a chain are suitable for LUC. With this approach, using the ArcGIS software, seven large areas were identified. In these seven zones, the land use change with no food crops is possible (Figure 5), without affecting important agricultural land context. The areas identified are only partially convertible.

The total amount of recoverable biomass and its energy value was estimated as reported in Table 1 and Table 2. The total amount of cereals actually produced, the energy cost for mechanization activity and the fertilization requirement were also estimated.

The predicted land use change does not affect all the suitable land, that is 150,000 ha, but only a fraction of these are eligible.

A possible scenario is the one in which, approximately, one-third of eligible zone change land use in the medium term, obtaining a scenario like the one presented in Table 3.

According to this scenario, about 50.000 ha would be converted to energy crops, which is a remarkable surface ( $4 \%$ of whole regional surface of $13,600 \mathrm{~km}^{2}$ ) but is quite small compared to Campania region's energy needs. In fact, the biomass production assessed has an energy value of about 160,000 toe/year, equivalent to about $1.5 \%$ of the regional energy needs, or only about $3.5 \%$ of the regional electricity demand.

Most results of interest are for the potential reduction of soil erosion risk and the reduction of fertilization and machining requirements.

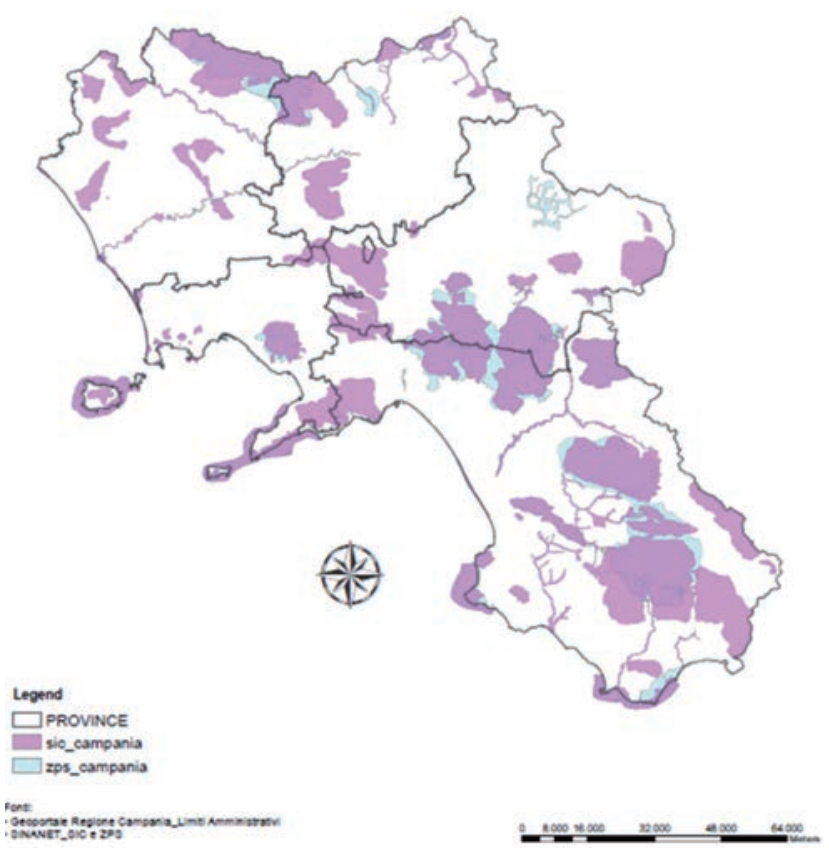

Figure 4. SCI and SPA. 


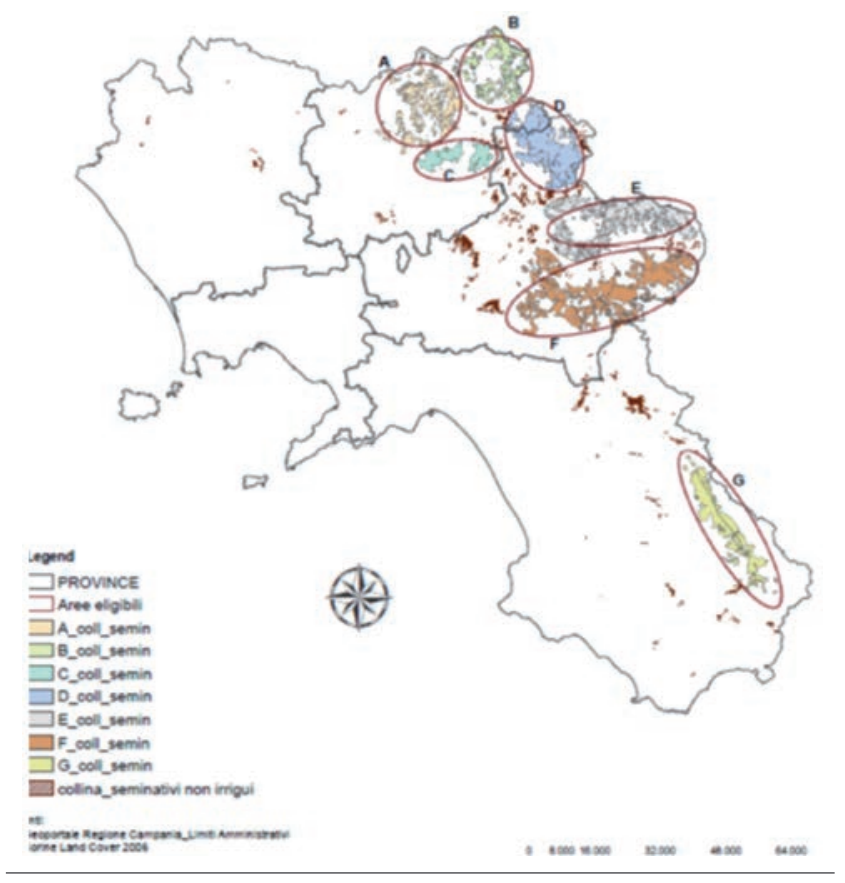

Figure 5. Macroareas resulting from the study.

\section{Conclusions}

It is possible to expect a large land use change into energy crops in Campania region. If the goal will be avoid overlap of biomass to arable lands, irrigated crops, parks and reserves, and other protected areas the eligible area remains only $1500 \mathrm{~km}^{2}$. Of these $1500 \mathrm{~km}^{2}$ it is reasonable to suppose a LUC of only 50,000 ha.

Measures aimed to increased land use change over this value, will lead to conflict with agriculture and environmental constraints.

In this scenario, even with this important LUC, the produced biomass, as an order of dimension, may only compensate the average increase in energy demand of one year in Campania Region.

Value of the biomass production, according to the hypothesis of this study, has been evaluated in the order of 25 million euro a year (assuming a unit price of biomasses of $30 € / t$ at the plant). This value has to be compared to the value of the actual wheat production, in the same areas. It would be 33 million euro a year (assuming a unit price of 270 $€ / t$ of wheat) and would appear more profitable but the production costs are far greater.

Considering the Land Use Change with Arundo donax there is a reduction in soil erosion in the order of 300,000 tyear that is one of the main goal of the LUC. This would lead to a saving, on a global scale, in terms of working and fertilization activities, in the order of 10 million tonnes of $\mathrm{CO}_{2}$ per year.

Table 1. Comparison between biomass produced with actual land use (wheat) and the supposed new land use (Arundo donax).

\begin{tabular}{|c|c|c|c|c|c|c|c|c|}
\hline & Zone A & Zone B & Zone C & Zone D & Zone E & Zone F & Zone G & Total \\
\hline Surface of the eligible area (ha) & $10 \cdot 446$ & 73713 & 5209 & 15483 & 18.046 & $19 \cdot 987$ & $9 \cdot 497$ & 152381 \\
\hline Straw availability (t/year) & $13 \cdot 985$ & $98 \cdot 683$ & 6.974 & 20728 & $24 \cdot 159$ & $26 \cdot 758$ & 12714 & $204: 000$ \\
\hline Arundo donax availability (t/year) & 122845 & 8668865 & 61258 & $182 \cdot 080$ & $212: 221$ & 235047 & $111 \cdot 685$ & $1792 \cdot 001$ \\
\hline Available energy of straw (toe/year) & 4867 & $34 \cdot 342$ & 2427 & 72213 & 8407 & $9 \cdot 312$ & $4 \cdot 425$ & $70 \cdot 992$ \\
\hline Available energy from Arundo donax (toe/year) & 33905 & $239 \cdot 255$ & 16.907 & 50254 & $58: 573$ & 64873 & $30 \cdot 825$ & 4945592 \\
\hline
\end{tabular}

Table 2. Surface eligible for LUC, surface supposed interested to LUC and production, reduction of predicted erosion.

\begin{tabular}{|c|c|c|c|c|c|c|c|c|}
\hline & Zone A & Zone B & Zone C & Zone D & Zone E & Zone F & Zone G & Total \\
\hline Surface of the eligible area (ha) & 10.446 & $73 \cdot 713$ & $5 \cdot 209$ & 15483 & $18 \cdot 046$ & $19 \cdot 987$ & $9 \cdot 497$ & 152381 \\
\hline Average of soil loss with wheat crop (tha ) & 3.51 & 8.938 & 3.83 & 4.89 & 2.968 & 6.796 & 1.555 & \\
\hline Average of soil loss with Arundo donax (t/ha) & 0.47 & 1.19 & 0.51 & 0.65 & 0.40 & 0.91 & 0.21 & \\
\hline Predicted annual soil loss with wheat (tyear) & 36697 & $658 \cdot 847$ & $19 \cdot 950$ & 75712 & $53 \cdot 561$ & 135832 & 14768 & 95366 \\
\hline Predicted annual soil loss with Arundo donax (tyear) & $4 \cdot 893$ & 87846 & 2660 & $10 \cdot 095$ & $7 \cdot 141$ & $18 \cdot 111$ & 19969 & 32715 \\
\hline Predicted soil loss reduction (t/year) & -31.804 & $-571^{\circ} 001$ & -17290 & -65617 & $-46 \cdot 419$ & -1177721 & -12799 & -862650 \\
\hline
\end{tabular}

Table 3. Evaluation of the consequence of the land use change only a part of eligibile areas.

\begin{tabular}{|c|c|c|c|c|c|c|c|c|}
\hline & Zone A & Zone B & Zone C & Zone D & Zone E & Zone $\mathrm{F}$ & Zone G & Total \\
\hline Surface of the eligible area (ha) & $10^{\circ} 446$ & $73 \cdot 713$ & $5 \cdot 209$ & $15 \div 483$ & $18 \cdot 046$ & $19 \cdot 987$ & $9 \cdot 497$ & 152381 \\
\hline Surface with LUC (1/3 of the eligible) (ha) & $3 \cdot 482$ & $24 \cdot 571$ & 1736 & $5: 161$ & 6.015 & 6662 & $3 \cdot 166$ & $50 \cdot 794$ \\
\hline Estimated production of Arundo donax (t/year) & $40 \cdot 948$ & $288 \cdot 955$ & 20419 & 60693 & $70 \cdot 740$ & $78 \cdot 349$ & $37 \cdot 228$ & $597: 334$ \\
\hline $\begin{array}{l}\text { Total energy value of Arundo donax; change supposed } \\
\text { in } 1 / 3 \text { of the eligible surface (toe/year) }\end{array}$ & 11302 & $79 \cdot 752$ & 5.636 & 16751 & $19 \cdot 524$ & 21624 & $10 \cdot 275$ & $164^{\circ} 864$ \\
\hline Potential reduction of soil losses (t/year) & -10601 & $-190 \cdot 334$ & -5763 & $-21 \cdot 872$ & $-15 \div 43$ & $-39 \cdot 240$ & -4266 & $-287 ` 550$ \\
\hline
\end{tabular}




\section{References}

De Philippis A. 1937. Classificazione ed indici del clima in rapporto alla vegetazione forestale italiana. N. G. B. I. ns, 44(1); 1-169.

I sistemi di terre della Campania. Carta 1:250.000 e Legenda. Available from: http://www.risorsa.info/files/SK_Carta.htm; Accessed: March 2013.

Di Gennaro A., Innamorato F. P., 2005. Verso l'identificazione dei paesaggi della Campania. Cartografia 1:250.000. Regione Campania, Assessorato al Governo del Territorio. Selca, Firenze

Diodato N., Fagnano M., Alberico I., 2009. CliFERM Climate Forcing and Erosion Response Modelling at Long-Term Sele River Research Basin (Southern Italy). Nat Hazard Earth Sys, 9: 1693-1702.

Fabiani G., Favia F. 1990. Vitalismo produttivo e precarietà strutturale nell'agricoltura campana contemporanea. Studi sull'agricoltura italiana. 25: 586

Fagnano M., Boccia L., Pindozzi S., Infascelli R., Faugno S. 2012.a. Aree Potenzialmente Convertibili a Colture Energetiche: Caso Studio della Regione Campania. Proc. XLI convegno nazionale della società italiana di agronomia. Bari (Italy). Not numbered volumes. Pp 464-466, Ecumenica Editrice scrl, Bari

Fagnano M., Diodato N., Alberico I., Fiorentino N. 2012.b An overview of soil erosion modeling compatible with RUSLE approach. Rend. Fis. Acc. Lincei, 23:69-80.

Lambin E.F., Turner B.L., Geist H.J., Agbola S.B., Angelsen A., Bruce
J.W., Coomes 0.T., Dirzo R., Fischer G., Folke C., George P.S., Homewood K., Imbernon J., Leemans R., Li X., Moran E.F., Mortimore M., Ramakrishnan P.S., Richards J.F., Skanes H., Steffen W., Stone G.D., Svedin U., Veldkamp T.A., Vogel C., Xu J., 2001. The causes of land-use and land-cover change: moving beyond the myths. Glob. Environ. Change., 11: 261-269.

Pelorosso R., Leone A., Boccia L., 2009. Land cover and land use change in the Italian central Apennines: A comparison of assessment methods. Appl. Geogr., 29: 35-48.

Summer W., Klaghofer E., Zhang W., 1998. Modelling Soil Erosion, Sediment Transport and Closely Related Hydrological Process. Proc. of an International Symposium Held at Vienna. IAHS-AISH Publication N.249, pp.453.

Wischmeier W. H. 1959. A rainfall erosion index for a universal soil loss equation. Soil Science Society of American Journal Procedures. 23:246-249.

Wischmeier W.H., Mannering J.V. 1969. Relation of soil properties to its erodibility. Soil Science Society of America Proceedings. 23:131137.

Wischmeier W. H., Johnson C. B., Cross B. V., 1971. A soil erodibility nomograph for farmland and construction sites. Journal of Soil and Water Conservation 26:189- 193.

Wischmeier W. H., Smith D. D., 1978. Predicting rainfall erosion losses: A guide to conservation planning. U.S. Department of Agriculture, Washington, DC, USA. Agriculture Handbook 537. 